\section{Evaluation of Radio Frequency-Hot Water Treatments for Postharvest Control of Codling Moth in 'Bing' Sweet Cherries}

\author{
J.D. Hansen ${ }^{1}$, S.R. Drake ${ }^{2}$, M.L. Heidt ${ }^{1}$, M.A. Watkins ${ }^{1}$, \\ J. Tang ${ }^{3}$, and S. Wang ${ }^{3}$
}

ADDITIONAL INDEX WORDS. Cydia pomonella, heat treatment, quarantine, fruit quality

$\overline{\text { Summary. Quarantine regulations require domestic sweet cherries (Prunus avium) }}$ exported to Japan to be treated to control codling moth [Cydia pomonella (Lepidoptera: Tortricidae)]. The current procedure, methyl bromide fumigation, may be discontinued because of health, safety, and environmental concerns. To examine a potential alternative method, 'Bing' sweet cherries were each infested with a codling moth larva, submerged in a $38^{\circ} \mathrm{C}$ water bath for 6 minutes pretreatment, then exposed to various temperatures generated by radio frequency and held at that temperature for different times: $50{ }^{\circ} \mathrm{C}$ for 6 minutes, $51.6^{\circ} \mathrm{C}$ for 4 minutes, $53.3{ }^{\circ} \mathrm{C}$ for 0.5 minutes, and $54.4^{\circ} \mathrm{C}$ for 0.5 minutes. Insect mortality was evaluated 24 hours after treatment and fruit quality was evaluated after treatment and after 7 and 14 days of storage at $1{ }^{\circ} \mathrm{C}$. No larvae survived at the 50 and $51.6^{\circ} \mathrm{C}$ treatments. Fruit color of non-infested cherries was darkened as temperature increased. Stem color was severely impacted after 7 days of storage, even in a warm water bath of $38{ }^{\circ} \mathrm{C}$ for 6 minutes, as was fruit firmness at the same treatment. Fruit quality loss increased after 14 days of storage, compared to after 7 days of storage. The amount of pitting and bruising of cherries increased with temperature and again this increase was more evident after 14 days of storage.

J apan is a primary market for exports of fresh sweet cherries from the Pacific states. Even though larvae of the codling moth may not occur naturally in cherries (Hansen and Lewis, 2003; Hansen et al., 2003; Wearing and McLaren, 2001; Wearing et al., 2001,), quarantine regulations require that domestic sweet cherries must be fumigated with methyl bromide before export to Japan (Hansen et al., 2000; Moffit et al., 1992). However, the future of methyl bromide is uncertain because of environmental health concerns, and international agreements restrict the production and use of this product (United Nations Environmental Programme, 1992). The U.S. Environmental Protection Agency (2004) has exempted the production and import of methyl bromide for selected quarantine and phytosanitation uses for 2005, but these exemptions are not routine and must be negotiated yearly. To continue to export sweet cherries, alternatives to methyl bromide fumigation must be developed.

Thermal treatments, particularly those initiated by radio frequency $(R F)$, have been proposed (Ikediala et al., 1999, 2002; Tang et al., 2000; Wang et al., 2003). The advantages of RF are that it is very fast, can penetrate fruit to the core, does not involve dangerous chemicals, and leaves no residues. The disadvantages of RF are the circuitline requirements for installation and non-uniformity of heating. Hansen et al. (2004b) calculated the amount of heat needed to control codling moth larvae in cherries, but reported fruit damage. Feng et al. (2004) used hot water to control codling moth that had artificially infested, freshly harvested California 'Bing' cherries, which maintained acceptable fruit quality for only a short period. If fruit injury could be reduced by faster heating, then further evaluation was needed to identify the time-temperature parameters used in RF-hot water bath combinations to effectively control codling moth larvae and to conduct quality tests on these treated fruit. The objectives of our study were to identify the time-temperature parameters needed for efficacy and to evaluate fruit quality at these settings.

\section{Material and methods}

Fruit infestation. Codling moth larvae came from the colony reared at the USDA-ARS Yakima Agricultural Research Laboratory in Wapato, Wash., where they were maintained $>300$ generations on a soy-wheat germ-starch artificial diet at $\sim 27{ }^{\circ} \mathrm{C}, 40 \%$ to $58 \%$ relative humidity $(\mathrm{RH})$, with a 16 -h light/8-h dark photoperiod (Toba and Howell, 1991). Third instars were used to infest fruit, which is the required life stage for evaluation in previous quarantine tests of codling moth on cherries exported to Japan (Hansen et al., 2000). Mature 'Bing' cherries were harvested from three orchards located in Washington state (Yakima, Wenatchee, and Stelmilt Hill). Cherries were transported on the day of harvest to the USDA-ARS Yakima Agricultural Research Laboratory (Wapato, Wash.) and treated separately according to location the following day. Each of 50 fruit per treatment replicate was infested with a larva at the stem end, and then every infested fruit was held overnight in a controlled-environment room at $25^{\circ} \mathrm{C}$ within a separate, sealed l-fl oz cup to allow larval penetration in the fruit. Potential treatments based on set temperature durations, and those at the same temperatures but at reduced time periods, were rejected if any survivor was found that resulted in
${ }^{3}$ Department of Biological Systems Engineering, Washington State University, Pullman, WA 99164-6120.

Acknowledgments: We are grateful to the following for their support: J. Weenink, T. Gorrebeeck, (ARS, Wapato, Wash.); J. Archer and F. Scarlett (Northwest Fruit Exporters, Yakima). We thank Tony Koral (Strayfield Fastran, Wokingham, U.K.) for his advice and recommendations. The manuscript was reviewed by P. Landolt (ARS, Wapato), R. Hilton (Oregon State Univ., Central Point), and M. Hennessey, (APHIS, Raleigh, N.C.). Partial funding for this research was from the Washington Tree Fruit Research Commission. Mention of a proprietary product does not constitute an endorsement or recommendation by USDA for its use.

To whom correspondence should be addressed: James D. Hansen: phone: 509-454-6573; fax: 509-454-5646; e-mail: jimbob@yarl.ars.usda.gov

\begin{tabular}{llll}
\hline $\begin{array}{l}\text { Units } \\
\text { To convert } \\
\text { U.S. to SI, }\end{array}$ & & & \\
multiply by & U.S. unit & SI unit & $\begin{array}{l}\text { To convert } \\
\text { SI to U.S., } \\
\text { multiply by }\end{array}$ \\
\hline 29.5735 & fl oz & $\mathrm{mL}$ & 0.0338 \\
3.7854 & gal & $\mathrm{L}$ & 0.2642 \\
0.7457 & horsepower & $\mathrm{kW}$ & 1.3410 \\
2.5400 & inch $(\mathrm{es})$ & $\mathrm{cm}$ & 0.3937 \\
25.4000 & inch $(\mathrm{es})$ & $\mathrm{mm}$ & 0.0394 \\
1000 & mmho $/ \mathrm{cm}$ & $\mu \mathrm{\mu S} \cdot \mathrm{cm}^{-1}$ & 0.0010 \\
$\left({ }^{\circ} \mathrm{F}-32\right) \div 1.8$ & ${ }^{\circ} \mathrm{F}$ & ${ }^{\circ} \mathrm{C}$ & $\left(1.8 \times{ }^{\circ} \mathrm{C}\right)+32$
\end{tabular}


Table 1. Survivorship of third instar codling moth infesting Washington state cherries (one larva per fruit) heated in a radio frequency unit after submersion in $38^{\circ} \mathrm{C}$ water bath for $6 \mathrm{~min}$ and held at set temperatures ${ }^{z}$ for specific times.

\begin{tabular}{lccccc}
\hline $\begin{array}{l}\text { Temp } \\
\left({ }^{\circ} \mathbf{C}\right)\end{array}$ & $\begin{array}{c}\text { Time } \\
(\mathbf{m i n})\end{array}$ & $\begin{array}{c}\text { Replicates } \\
(\text { no. })\end{array}$ & $\begin{array}{c}\text { Total } \\
\text { treated }(\text { no. })\end{array}$ & $\begin{array}{c}\text { Live } \\
(\text { no. })\end{array}$ & $\begin{array}{c}\text { Live } \\
(\%)\end{array}$ \\
\hline $24^{\mathrm{x}}$ & 6 & 10 & 500 & 462 & 92.4 \\
$38^{\mathrm{w}}$ & 6 & 10 & 500 & 467 & 93.4 \\
50 & 4 & 4 & 200 & 0 & 0 \\
50 & 5 & 4 & 200 & 0 & 0 \\
50 & 6 & 10 & 500 & 0 & 0 \\
51.6 & 2 & 3 & 150 & 0 & 0 \\
51.6 & 3 & 4 & 200 & 0 & 0 \\
51.6 & 4 & 6 & 300 & 0 & 0 \\
51.6 & 6 & 2 & 100 & 0 & 0 \\
53.3 & $1 / 2$ & 7 & 350 & 1 & 0.3 \\
53.3 & 1 & 2 & 100 & 0 & 0 \\
54.4 & $1 / 2$ & 6 & 300 & 8 & 2.7 \\
54.4 & 1 & 3 & 150 & 1 & 0.7 \\
\hline
\end{tabular}

${ }^{2}\left(1.8 \times{ }^{\circ} \mathrm{C}\right)+32^{\circ}={ }^{\circ} \mathrm{F}$

y 50 larvae per replicate.

'Untreated control.

wretreatment control.

unequal replication among the treatments (Table 1).

EXPERIMENTAL Unit. Tests were performed in a $12-\mathrm{kW}$ Fastran Radio Frequency heater/dryer with an E-200 control panel (Strayfield International Ltd., Wokingham, U.K.), with the frequency set at $27.12 \mathrm{MHz}$ (Hansen et al., 2004a). Energy was induced between the electrodes by a high-energy RF oscillator (Tang et al., 2000; Wang et al., 2001). The maximum electrical current was 2 amperes based on the $12-\mathrm{kW}$ power capacity of the unit. Power applied to the target material was adjusted by lowering or raising the top electrode, changing the dimensions of the target, and by varying the amount of mass (load). Because metal would interact with the electromagnetic field, material exposed to radio frequency was restricted to vegetable matter, water, and polypropylene plastic.

TreatmenTs. In preparation for treatment, cherries were placed in a cotton organdy mesh bag and the opening sealed with rubber bands. Infested fruit were treated directly out of the holding room, exposed to a pretreatment based on fruit heating studies to reduce fruit injury (S.R. Drake et al., unpublished), heat treated, and efficacy evaluated the treatment the following day. For each treatment, 50 cherries in bags were placed into a specially built polypropylene tank $(17.5 \mathrm{~cm}$ high and $27 \mathrm{~cm}$ in diameter) holding $10 \mathrm{~L}$ of 38 ${ }^{\circ} \mathrm{C}$ tap water. Water circulated within the tank by the use of a two-speed, 1.5horsepower Century Lasar Pool/Spa
Motor Pump (Aqua-flo Inc., Chino, Calif.) located outside the unit. Water conductivity was adjusted to 450 to 475 $\mu \mathrm{S} \cdot \mathrm{cm}^{-1}$ by adding $2 \mathrm{~mL}$ of sodium hypochlorite and about $5 \mathrm{~mL}$ of calcium chloride. Fruit were held in the warm water for $6 \mathrm{~min}$ before RF exposure to increase fruit pulp temperature before treatment (the pretreatment).

Internal fruit temperatures (2 $\mathrm{cm}$ deep) were measured by inserting a fiber optic transducer probe with $0.12{ }^{\circ} \mathrm{C}$ resolution (model FOT-L/ CRM/3m; FISO Technologies Inc., Sainte-Foy, Que., Canada), in each of two cherries, near the stem into the middle of the cherry pulp halfway between the pit and the outer skin of the fruit. A third probe was used in the tank to measure water temperature. Data acquisition was performed using the FISO Commandersoftware (FISO Technologies Inc.) with temperatures measured every $0.05 \mathrm{~s}$.

All RF treatments were performed starting with a gap of $24 \mathrm{~cm}$ with initial amperage at 1.9 to 2.0. The RF machine then automatically adjusted the gap to around $25.5 \mathrm{~cm}$ to maintain the maximum power. Once the cherry on the fiber optic probe with the lower temperature reached the target temperature (mean \pm SE of difference between two cherry temperatures = $\left.1.0 \pm 0.1^{\circ} \mathrm{C}, n=69\right)$, RF heating was stopped. The upper electrode plate was then raised to a gap of $40 \mathrm{~cm}$, and cherries were left in circulating water for the predetermined holding period. The treatments consisted of four temperatures at different holding periods: $50{ }^{\circ} \mathrm{C}$ for 4,5 , or $6 \mathrm{~min}$; $51.6^{\circ} \mathrm{C}$ for $2,3,4$, or $6 \mathrm{~min} ; 53.3^{\circ} \mathrm{C}$ for 0.5 or $1.0 \mathrm{~min} ; 54.4^{\circ} \mathrm{C}$ for 0.5 or $1 \mathrm{~min}$. Temperatures were based on earlier experimental studies and the durations were the estimated minimum times from Wang et al. (2002) and Hansen et al. (2004b). Treatments were compared to two controls: cherries circulating in tap water at $25^{\circ} \mathrm{C}$ for $6 \mathrm{~min}$ and at $38^{\circ} \mathrm{C}$ for $6 \mathrm{~min}$. After treatment, fruit were cooled for $8 \mathrm{~min}$ in a $0{ }^{\circ} \mathrm{C}$ water bath.

Fruit Quality eValuations. To simulate commercial conditions (Ikediala et al., 1999; Hansen et al., 2000; Shellie et al., 2001), fruit quality evaluations were determined after $\mathrm{l}$ and 2 weeks of cold storage at $1{ }^{\circ} \mathrm{C}$ and $90 \% \mathrm{RH}$ following treatment as previously described for the efficacy tests. Three replicates per treatment were used with 30 fruit/treatment/ replicate. The quality evaluations consisted of objective and subjective color, firmness, soluble solids content (SSC), titratable acidity (TA) and evaluation for defects (visible burn, rots, internal breakdown). Objective color of the fruit and stems was determined with a colorimeter (ColorFlex, model 45/0; Hunter Assoc., Reston, Va.) using the $\mathrm{L}^{*}, \mathrm{a}^{*}, \mathrm{~b}^{*}$ system and calculated hue values (Hunter and Harold, 1987). Firmness was determined using the Universal TA-XT2 texture analyzer (Texture Technologies, Scarsdale, N.Y.) equipped with an 11-mm probe with a penetration distance after contact of $7 \mathrm{~mm}$ and values were expressed in Newtons. SSC of the fruit were determined with an Abbe-type refractometer with a sucrose scale calibrated at $20^{\circ} \mathrm{C}$. Acids were titrated to $\mathrm{pH} 8.2$ with 0.1 $\mathrm{N}$ sodium hydroxide and expressed as percentage of malic acid. Visual defects of the fruit (burn, pitting, bruising, rot, internal breakdown) and stem (burn) were evaluated by laboratory personnel and reported as percent of the total fruit or stem with any defect. Subjective quality (color) of both fruit and stem was evaluated by the same laboratory personnel and graded on a scale of 1 to $4(1=$ excellent; $2=$ good; $3=$ fair; $4=$ poor). Fruit or stems receiving subjective scores $>2.5$ were considered unacceptable.

Data analysis. Temperature and survival data were entered into Quattro Pro 10 spreadsheets (Corel Corp. Ltd., Ottawa, Ont., Canada). 
Table 2. Fruit quality values of mature 'Bing' cherries after radio frequency exposures to reach treatment temperatures ${ }^{\mathrm{z}}$ and held for set times.

\begin{tabular}{|c|c|c|c|c|c|c|c|c|c|c|c|c|}
\hline \multirow[b]{3}{*}{ Source $^{y}$} & \multicolumn{2}{|c|}{ Treatment } & \multirow[b]{3}{*}{ Week } & \multirow{2}{*}{\multicolumn{3}{|c|}{ Fruit }} & \multirow{2}{*}{\multicolumn{3}{|c|}{ Stem }} & \multirow[b]{3}{*}{ SSC $(\%)^{\mathrm{v}}$} & \multirow[b]{3}{*}{$\mathrm{Pit}^{\mathrm{u}}$} & \multirow[b]{3}{*}{ Bruise $^{u}$} \\
\hline & \multirow{2}{*}{$\begin{array}{l}\text { Temp } \\
\left({ }^{\circ} \mathrm{C}\right) \\
\end{array}$} & \multirow{2}{*}{$\begin{array}{l}\text { Time } \\
(\min )\end{array}$} & & & & & & & & & & \\
\hline & & & & $L^{x}$ & Hue $^{x}$ & Vis. ${ }^{\mathrm{w}}$ & $L^{x}$ & Hue $^{x}$ & Vis. ${ }^{\mathrm{w}}$ & & & \\
\hline \multirow[t]{10}{*}{1} & $25^{\mathrm{t}}$ & 6 & 1 & 22.9 & 15.7 & 1.0 & 26.7 & 95.1 & 1.6 & 20.8 & 1.0 & 1.0 \\
\hline & 50 & 6 & 1 & 23.9 & 15.0 & 1.1 & $20.6^{* *}$ & $72.4^{*}$ & $2.5^{* *}$ & 20.4 & 1.0 & 1.0 \\
\hline & 51.6 & 4 & 1 & $24.6^{* \mathrm{r}}$ & $13.3^{*}$ & $1.3^{*}$ & $19.5^{* *}$ & $63.2^{* *}$ & $3.0^{\star \star}$ & 20.2 & 1.1 & 1.2 \\
\hline & 53.3 & 0.5 & 1 & $24.8^{*}$ & $10.8^{\star *}$ & $1.3^{*}$ & $17.6^{* *}$ & $58.2^{\star \star}$ & $3.5^{* *}$ & 20.6 & 1.2 & 1.1 \\
\hline & 25 & 6 & 2 & 22.9 & 12.2 & 1.1 & 25.7 & 90.3 & 2.0 & 20.5 & 1.1 & 1.0 \\
\hline & 38 & 6 & 2 & 22.8 & $6.6^{*}$ & $1.8^{*}$ & 23.4 & 78.6 & $2.6^{* \star}$ & 20.5 & 1.5 & 1.0 \\
\hline & 50 & 6 & 2 & 23.3 & $8.3^{*}$ & $2.1^{\star *}$ & $18.7^{* *}$ & $67.7^{\star *}$ & $2.8^{* *}$ & 19.7 & $1.8^{*}$ & $1.6^{* *}$ \\
\hline & 51.6 & 4 & 2 & 23.6 & $8.6^{* *}$ & $2.5^{\star *}$ & $18.6^{* *}$ & $62.6^{* *}$ & $3.4^{* *}$ & $20.0^{*}$ & $1.9^{\star *}$ & $2.0^{* *}$ \\
\hline & 53.3 & 0.5 & 2 & 24.1 & $6.1^{* *}$ & $2.8^{* *}$ & $17.6^{* *}$ & $55.7^{\star *}$ & $4.0^{* *}$ & 20.2 & $2.6^{* *}$ & $2.4^{* *}$ \\
\hline & 54.4 & 0.5 & 2 & $25.6^{*}$ & 8.1 & $2.4^{* *}$ & $17.3^{* *}$ & $54.4^{\star \star}$ & $4.0^{* *}$ & $19.5^{* *}$ & $2.3^{*}$ & $2.1^{* *}$ \\
\hline & 51.6 & 4 & 1 & $25.6^{* *}$ & 22.0 & $2.0^{* *}$ & $19.3^{* *}$ & $71.1^{* *}$ & $3.3^{* *}$ & 23.1 & 1.2 & $2.0^{*}$ \\
\hline & 53.3 & 0.5 & 1 & $26.1^{\star *}$ & $19.1^{\star *}$ & 1.2 & $22.5^{*}$ & $85.5^{\star \star}$ & $2.8^{* \star}$ & 22.4 & 1.1 & $1.2^{\star \star}$ \\
\hline & 54.4 & 0.5 & 1 & $26.3^{\star *}$ & $20.1^{*}$ & $2.1^{\star *}$ & $18.6^{* *}$ & $64.6^{*}$ & $3.7^{* *}$ & 22.0 & 1.4 & $1.8^{* *}$ \\
\hline & 25 & 6 & 2 & 24.7 & 14.0 & 1.6 & 27.4 & 103.8 & 1.9 & 23.1 & 1.0 & 1.0 \\
\hline & 38 & 6 & 2 & 25.1 & 15.3 & $2.1^{*}$ & $23.1^{*}$ & $87.2^{*}$ & $2.9^{* *}$ & $21.5^{*}$ & 1.3 & $1.3^{*}$ \\
\hline & 50 & 6 & 2 & 24.0 & $17.3^{*}$ & $2.3^{*}$ & $20.3^{* *}$ & $78.4^{*}$ & $3.8^{* *}$ & 22.3 & $1.8^{*}$ & $2.0^{*}$ \\
\hline & 51.6 & 4 & 2 & 23.7 & 16.1 & $2.9^{* *}$ & $17.9^{* *}$ & $59.2^{\star \star}$ & $4.0^{* *}$ & $24.4^{*}$ & $2.5^{\star *}$ & $2.3^{* *}$ \\
\hline & 53.3 & 0.5 & 2 & 25.8 & 15.6 & $2.2^{*}$ & $20.1^{* *}$ & $78.5^{* *}$ & $3.7^{* *}$ & 22.5 & $2.3^{* \star}$ & $1.5^{* *}$ \\
\hline & 54.4 & 0.5 & 2 & 24.9 & 15.5 & $2.8^{* *}$ & $17.9^{* *}$ & $60.3^{\star \star}$ & $4.0^{* *}$ & 22.4 & $2.5^{* *}$ & $2.2^{* *}$ \\
\hline \multirow[t]{4}{*}{3} & 25 & 6 & 1 & 23.8 & 13.5 & 1.3 & 29.6 & 102.3 & 1.3 & 23.1 & 1.2 & 1.0 \\
\hline & 38 & 6 & 1 & 24.6 & 12.5 & 1.4 & $23.5^{\star}$ & $80.6^{*}$ & $2.5^{* \star}$ & 23.9 & 1.0 & 1.0 \\
\hline & 53.3 & 0.5 & 2 & 21.5 & 24.6 & $2.8^{* *}$ & $19.5^{* *}$ & $63.8^{\star *}$ & $3.8^{* *}$ & 23.0 & $2.8^{* *}$ & $2.7^{\star \star}$ \\
\hline & 54.4 & 0.5 & 2 & $22.2^{\star *}$ & 25.1 & $3.2^{\star *}$ & $17.3^{* *}$ & $51.9^{* *}$ & $4.0^{* \star}$ & 22.3 & $3.2^{* *}$ & $2.6^{* *}$ \\
\hline
\end{tabular}

${ }^{z}\left(1.8 \times{ }^{\circ} \mathrm{C}\right)+32^{\circ}={ }^{\circ} \mathrm{F}$.
ySource (all Washington state): 1 = Yakima; 2 = Wenatchee; $3=$ Stemilt Hill.

${ }^{x}$ Objective color determined with a colorimeter (ColorFlex, model 45/0; Hunter Assoc., Reston, Va.) using the L*, a* $b^{*}$ Hunter system.

${ }^{w}$ Vis. $=$ visual observation of fruit quality; scale: $1=$ excellent; $2=\operatorname{good} ; 3=$ fair; $4=$ poor.

vSS $=$ soluble solids content.

"Pit/bruise = visual measurement of pitting and bruising; scale: 1 = excellent; 2 = good; 3 = fair; 4 = poor.

tUntreated control.

sPretreatment control

rComparison tests by $t$ test between control $\left(25^{\circ} \mathrm{C}\right)$ and treated.

${ }^{*},{ }^{* *}$ Significant at $P \leq 0.05$ or 0.01 , respectively.

Univariate statistics were calculated by using means procedure and analysis of variance was conducted on the fruit quality parameter data by using the general linear model procedure (SAS Institute, Cary, N.C.). Because quarantine security has a strict standard (no survivors in 30,000 treated population ) (Hansen et al., 2000), efficacy data were summed by treatment.

\section{Results and discussion}

Although Ikediala et al. (2002) did initial studies on the effect of RF heating on codling moth in cherries, our study was the first attempt to define heating parameters for efficacious codling moth control $(99.9986 \%$ mortality of treated population) and to record extensive fruit quality values for those treatments. The pretreatment at $38^{\circ} \mathrm{C}$ used immediately before the radio frequency did not increase larval mortality (Table 1 ). No survivors were found from the 50 and $51.6^{\circ} \mathrm{C}$ treatments, which had the longest exposure times. No larvae survived the $53.3^{\circ} \mathrm{C}$ treatment for $1 \mathrm{~min}$, but larval survival for $53.3^{\circ} \mathrm{C}$ for $0.5 \mathrm{~min}$ and both 54.4 ${ }^{\circ} \mathrm{C}$ treatments precluded both 53.3 and $54.4^{\circ} \mathrm{C}$ procedures from becoming quarantine treatments.

Post-treatment fruit quality was evaluated after 7 and $14 \mathrm{~d}$ of storage at $1^{\circ} \mathrm{C}$. Fruit color of non-infested cherries darkened as temperature increased (Table 2). Fruit color values ( $a$ and $b$ ) also changed as temperature increased, but theses changes would not be visible 
to the consumer because hue values did not change with temperature. Stem color was severely impacted by heat generated by radio frequency. Stems in a warm water bath $\left(38^{\circ} \mathrm{C}\right.$ for $\left.6 \mathrm{~min}\right)$, a very mild heat treatment, darkened by 3.5 units ( $\mathrm{L}$ values). More darkening was evident when stems were exposed to higher temperatures. This darkening of the stems was accompanied with a reduction in green color and significantly lower hue values. A change of one unit in color is visible to the human eye. Cherry firmness was reduced even with a mild heat treatment (38 ${ }^{\circ} \mathrm{C}$ for $6 \mathrm{~min}$ ) and when cherries were exposed to higher temperature, loss of fruit firmness was very significant. Subjective quality evaluations of both cherry fruit and stem indicated that increased heat reduced both visual fruit and stem quality; after 2 weeks of storage this quality loss was even more evident. The amount of pitting and bruising of cherries increased with temperature and this increase was more evident after 2 weeks of storage. The same patterns of damage were observed for cherries from all sources, although those from Yakima seemed to have the most heat tolerant stems and those from Stemilt Hill had the most heat tolerant fruit (Table 2).

This study demonstrated the efficacy of using heat to control codling moth larvae infesting cherries. Thermal methods, including the use of radio frequency energy, have potential for replacing methyl bromide fumigation. However, all of the heat treatments used in this study, including the pretreatment at $38^{\circ} \mathrm{C}$ for $6 \mathrm{~min}$, resulted in unacceptable damage, particularly to the stems. Undamaged stems are an essential quality for the marketing of fresh cherries. Unless stem quality can be maintained, this procedure does not have any opportunity for success in its current form. Some procedure must be found to protect the stems during heat treatments. Fruit firmness also decreased at the higher temperatures, even during treatments that had larval survivors. Furthermore, treated fruit tended to deteriorate quicker than untreated fruit during storage. It is likely that increased respiration during the experiment resulted in accelerated fruit aging.

\section{Literature cited}

Feng, X, J.D. Hansen, B. Biasi, J. Tang, and E.J. Mitcham. 2004. Use of hot water treatment to control codling moths in harvested California 'Bing' sweet cherries. Postharvest Biol. Technol. 31:41-49.

Hansen, J.D., S.R. Drake, M.L. Heidt, M.A. Watkins, J. Tang, and S. Wang. 2004a. Radio frequency treatments for postharvest codling moth control in fresh apples. HortTechnology 14:533-537.

Hansen, J.D., S.R. Drake, H.R. Moffitt, D.J.Albano, and M.L. Heidt. 2000. Methyl bromide fumigation of five cultivars of sweet cherries as a quarantine treatment against codling moth. HortTechnology 10:194-198.

Hansen, J.D. and L.R. Lewis. 2003. Field survival of codling moth (Lepidoptera: Tortricidae) on artificially infested sweet cherries. Crop Protection 22:721-727.

Hansen, J.D., L.J. Rehmke, and G.F. Simmons. 2003. Packing house survey of Washington cherries for surface arthropods. J. Kansas Entomol. Soc. 76:76-78.

Hansen, J.D., S. Wang, and J. Tang. 2004b. A cumulated lethal time model to evaluate efficacy of heat treatments for codling moth Cydia pomonella (L.) (Lepidoptera: Tortricidae) in cherries. Postharvest Biol. Technol. 33:309-317.

Hunter, R.S. and R.W. Harold. 1987. The measurement of appearance. Wiley, New York.

Ikediala, J.N., J.D. Hansen, J. Tang, S.R. Drake, and S. Wang. 2002. Development of a saline water immersion technique with RF energy as a postharvest treatment against codling moth in cherries. Postharvest Biol. Technol. 24:25-37.

Ikediala, J.N., J. Tang, L.G. Neven, and S.R. Drake. 1999. Quarantine treatment of cherries using $915 \mathrm{MHz}$ microwaves: Temperature mapping, codling moth mortality and fruit quality. Postharvest Biol. Technol. 16:127-137.

Moffitt, H.R., S.R. Drake, H.H. Toba, and P.L. Hartsell. 1992. Comparative efficacy of methyl bromide against codling moth (Lepidoptera: Tortricidae) larvae in 'Bing' and 'Rainier' cherries and confirmation of efficacy of a quarantine treatment for 'Rainier' cherries. J. Econ. Entomol. 85:1855-1858.
Shellie, K.C., L.G. Neven, and S.R. Drake. 2001. Assessing 'Bing' sweet cherry tolerance to a heated controlled atmosphere for insect pest control. HortTechnology 11:308-311.

Tang, J. J.N. Ikediala, S. Wang, J.D. Hansen, and R.P. Cavalieri. 2000. Hightemperature short-time thermal quarantine methods. Postharvest Biol. Technol. 21:129-145.

Toba, H.H. and J.F. Howell. 1991. An improved system for mass-rearing codling moths. J. Entomol. Soc. Brit. Columbia $88: 22-27$.

United Nations Environmental Programme. 1992. Methyl bromide: Atmospheric science, technology \& economics. U.N. Headquarters, Ozone Secretariat, Nairobi, Kenya.

U.S. Environmental Protection Agency. 2004. Protection of stratospheric ozone: Process for exempting critical uses from the phaseout of methyl bromide. Code of Federal Regulat., Title 40, Part 82, [FRL-] RIN-2060-AJ63, Washington, D.C.

Wang, S., J.N. Ikediala, J. Tang, and J.D. Hansen. 2002. Thermal death kinetics and heating rate effects for fifth-instar Cydia pomonella(L.) (Lepidoptera: Tortricidae). J. Stored Prod. Res. 38:441-453.

Wang, S., J.N. Ikediala, J. Tang, J.D. Hansen, E. Mitcham, R. Mao, and B. Swanson. 2001. Radio frequency treatments to control codling moth in in-shell walnuts. Postharvest Biol. Technol. 22:29-38.

Wang, S., J. Tang, J.A. Johnson, E. Mitcham, J.D. Hansen, G. Hallman, S.R. Drake, and Y. Wang. 2003. Dielectric properties of fruits and insect pests as related to radio frequency and microwave treatments. Biosystems Eng. 85:201-212.

Wearing, C.H., J.D. Hansen, C. Whyte, C.E. Miller, and J. Brown. 2001. The potential for spread of codling moth (Lepidoptera: Tortricidae) via commercial sweet cherry fruit: A critical review and risk assessment. Crop Protection 20:465-488.

Wearing, C.H. and G.F. McLaren. 2001. Evidence that sweet cherry Prunus avium L. is not a host of codling moth, Cydia pomonella, (Lepidoptera: Tortricidae). Crop Protection 20:571-579. 